\title{
Rede Neural com Funções de Base Radial Aplicada à Estimativa de Chuva
}

\author{
Tiago Noronha dos Santos \\ UFPR - PPGMNE \\ 81531-970, Centro Politécnico, Curitiba, PR \\ E-mail: noronhati@gmail.com
}

Paulo Henrique Siqueira

UFPR - Departamento de Expressão Gráfica

81531-970, Centro Politécnico, Curitiba, PR

E-mail: paulo_hs@ufpr.br

\section{Leonardo Calvetti}

Instituto Tecnológico SIMEPAR

81531-970, Centro Politécnico, Curitiba, PR

E-mail: leonardo@simepar.br

\begin{abstract}
Resumo: Melhorar a acurácia da estimativa de chuvas em eventos meteorológicos é um grande desafio e o motivo de inúmeras pesquisas. Este trabalho utiliza Redes Neurais de Base Radial com o propósito de estabelecer uma relação mais próxima da real quando se fala em precipitação de chuva em superfície terrestre. Outras relações comumente utilizadas são ferramentas para comparações e validação da técnica proposta. Como fonte de informação para o estudo são utilizados dados provenientes do Instituto Tecnológico SIMEPAR, que coleta informações meteorológicas no estado do Paraná.
\end{abstract}

Palavras-chave: Redes Neurais Artificiais, Metaheurísticas, Rede Neural de Base Radial, Estimativa de Chuvas.

\section{Introdução}

Estimar a quantidade de chuva que deve chegar à supefície da Terra é uma tarefa que requer muitos estudos e novas metodologias. Essa é a ideia proposta no presente trabalho, que envolve os dados captados pelo radar meteorológico do SIMEPAR e uma rede de 18 pluviômetros localizados a um raio de $200 \mathrm{~km}$ do radar. A função da nova técnica é converter os dados de radar em precipitação de chuva de forma que os valores se aproximem ao máximo dos valores medidos pelos pluviômetros. O trabalho está disposto da seguinte forma: Na próxima seção especificamos os instrumentos de medição (Radar Meteorológico e Pluviômetros), em seguida, introduzimos o Fator de Refletividade do Radar, a técnica mais utilizada para a conversão de refletividade em precipitação de chuva (Relação ZR) e a teoria básica com a estrutura de uma Rede Neural de Base Radial. Concluímos apresentando e discutindo a nova técnica junto ao banco de dados selecionado para o treinamento e testes além de compararmos com a Relação ZR. 


\section{Instrumentos de Medição}

\subsection{Radar Meteorológico}

A tecnologia de radar meteorológico tem sido usada desde a Segunda Guerra Mundial, quando militares perceberam que a precipitação da chuva também aparecia nas telas dos radares que rastreavam aviões e navios inimigos. Desde então cientistas passaram a usar radares para estudar e monitorar as características do tempo. Um radar meteorológico trabalha através da emissão de pulsos de energia eletromagnética em frequência de micro-ondas para a atmosfera. Quando esses pulsos encontram algum objeto parte da energia é espalhada e retorna para o radar. Esta energia é muitas vezes referida como sendo "refletida" de volta, e é onde aparece o termo "refletividade". O funcionamento do radar poder ser simplificado da seguinte maneira: a antena é apontada em um ângulo baixo e emite um pulso eletromagnético por uma fração de segundo, e depois recebe o retorno da energia, em seguida o radar gira a quantidade aproximada de $1^{\circ}$ e repete o processo. Uma vez que o radar completa uma revolução o ângulo de elevação da antena Resumoé aumentado e repete-se o procedimento (Beneti, 1999). O Instituto Tecnológico SIMEPAR possui um radar meteorológico tipo Banda-S Doppler, localizado na cidade de Teixeira Soares-PR, o qual é utilizado na pesquisa. O radar pode cobrir tanto uma área de $480 \mathrm{~km}$ de raio partindo do radar, quanto uma área de $200 \mathrm{~km}$. Os dados utilizados neste trabalho são de $200 \mathrm{~km}$.

\subsection{Pluviômetro}

Pluviômetros são instrumentos para medir a precipitação de chuva. Existem vários modelos e formas de pluviômetros e dentre esses utilizaremos os chamados de tipping bucket (tipo báscula ou caçamba) que são os utilizados pelo SIMEPAR. Este tipo de pluviômetro envia um sinal elétrico (pulso) para cada unidade de precipitação coletada. Os tipping buckets consistem em duas caçambas triangulares ligadas à esquerda e à direita de um eixo de rotação, cada uma com a capacidade equivalente para uma determinada quantidade de precipitação. O interruptor é conectado a essas caçambas para gerar um sinal elétrico a cada vez que a caçamba enche, para este tipo de pluviômetro essa quantidade é de $0,2 \mathrm{~mm}$.

\section{Refletividade}

O parâmetro definido por Rinehart (2004), foi nomeado como Refletividade do Radar e pode ser representado pela letra $\mathrm{z}$, onde

$$
z=\sum D_{i}^{6}
$$

sendo, $D_{i}$ o diâmetro da gota $i$, e o somatório é feito sobre o total número de gotas de tamanhos variados dentro de uma unidade de volume de feixe. Para ilustrar, considere uma seção de 1 metro cúbico do feixe de radar que contém uma distribuição de gotas de chuva de tamanhos diferentes (Mueller, 2013), por exemplo, 19 gotas, cada uma identificada com o número de 1 a 19:

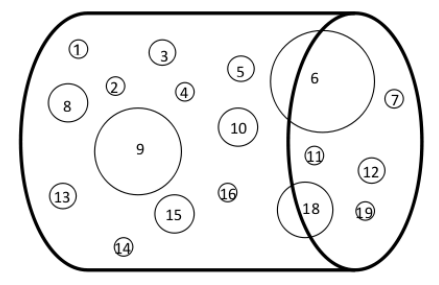

Figura 1: Exemplo de 1 metro cúbico de feixe de radar com uma distribuição de gotas de tamanhos diferentes. 
O somatório para o fator de refletividade do radar $z$ pode ser expandido assim:

$$
z=D_{1}^{6}+D_{2}^{6}+\ldots+D_{19}^{6}
$$

Nota-se que $z$ é uma propriedade inerente da distribuição do tamanho da gota e não depende do radar. Outro ponto importante é que $z$ é proporcional à sexta potência dos tamanhos de gota, logo, gotas maiores causam grandes valores de refletividade quando comparadas com gotas pequenas. Como o fator de refletividade do radar abrange um grande intervalo de magnitudes, de $0,0001 \mathrm{~mm}^{6} / \mathrm{m}^{3}$ para nevoeiro, até $36.000 .000 \mathrm{~mm}^{6} / \mathrm{m}^{3}$ para granizo do tamanho de uma bola de tênis, é geralmente expresso em decibéis de refletividade ou em $d B Z$ da seguinte forma:

$$
Z=10 \log _{10} z \frac{1 m m^{6}}{m^{3}}
$$

aqui é importante distinguir $Z$ de $z$. A transformação logarítmica aqui é usada para comprimir intervalos de grandes magnitudes em uma escala de valores mais compreensíveis.

\section{Relação ZR}

Existe uma relação entre a taxa de precipitação de chuva e a refletividade do radar.Distribuições de tamanhos de gotas medidos experimentalmente foram extensivamente utilizados para calcular ambos. Traçando a taxa de precipitação de chuva contra a refletividade ou correlacionando ambas estatisticamente, pode-se determinar a relação entre esses dois parâmetros. A relação matemática mais usada é a relação empírica exponencial

$$
z=A R^{b},
$$

onde $R$ é a taxa de precipitação $(m m / h), z$ é o fator de refletividade do radar $\left(m m^{6} / m^{3}\right)$, e $A$ e $b$ são constantes empíricas. Na realidade, mede-se a refletividade e então pode-se usá-la para calcular a taxa de precipitação de chuva. A Relação ZR mais comumente usada foi desenvolvida por Marshall e Palmer (Rinehart, 2004), $z=200 R^{1,6}$. Esta relação formou a base para muitas pesquisas e foi amplamente utilizada para calcular os valores de precipitação a partir dos dados de radar.

\section{Funções de Base Radial}

Uma Função de Base Radial (RBF - Radial Base Function) é definida como qualquer função que satisfaz a seguinte condição (Haykin, 2001)

$$
f(x)=f(\|x\|)
$$

ou seja, quando seus valores funcionais são iguais às normas de seus argumentos. Em outras palavras, uma função é de base radial quando seu valor funcional depende apenas da distância de seu argumento à origem. Há várias RBFs, neste trabalho utiliza-se a função gaussiana

$$
\varphi(x)=\exp \left(-\frac{x-\mu}{2 \sigma}\right) .
$$

\section{Redes Neurais de Base Radial}

Uma RBFNN (Radial Base Function Neural Network) utiliza funções de base radial como função de ativação dos neurônios da camada escondida (da Mota, 2011). A arquitetura de uma RBFNN é bastante simples, há apenas a camada com os nós de entrada, a camada oculta com as funções de base radial e uma camada de saída que possui funções lineares como ativação. 


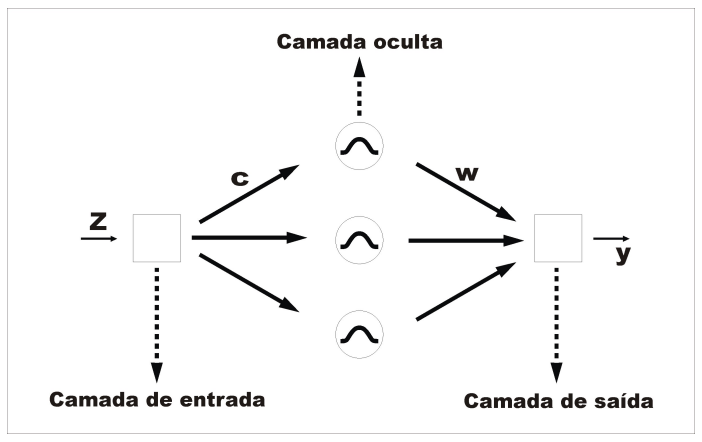

Figura 2: Modelo de arquitetura de uma RBFNN.

Cada neurônio da camada oculta possui um vetor associado, chamado de centro do neurônio, o qual define o centro do campo receptivo daquele neurônio. Estes neurônios exercem forte influência sobre o desempenho da rede. Seja $X \in \Re^{m x n}$ a matriz de observações contendo $n$ observações e $m$ variáveis, temos,

$$
X=\left(\begin{array}{ccc}
x_{11} & \cdots & x_{1 n} \\
\vdots & \ddots & \vdots \\
x_{m 1} & \cdots & x_{m n}
\end{array}\right)
$$

$\mathrm{O}$ valor de ativação do $m$-ésimo neurônio da camada escondida depende da distância euclidiana quadrática entre a entrada $x^{i}$ e o centro $c_{j}$, onde $c_{j} \in C$ é o centro do $m$-ésimo neurônio. Então, de acordo com a abordagem clássica, treinar uma RBFNN é, de fato, calcular a matriz de pesos,

$$
w=\left(\begin{array}{ccc}
w_{10} & \cdots & w_{1 s} \\
\vdots & \ddots & \vdots \\
w_{p 0} & \cdots & w_{p s}
\end{array}\right)
$$

de maneira a ajustar aos alvos $t$ cada $y$, como podemos ver na equação:

$$
y_{r}=w_{0 r} \varphi_{0 r}+\sum_{k=1}^{s} w_{k r} \varphi\left(\left\|x^{i}-C\right\|\right) .
$$

\section{Resultados e Conclusões}

A RBFNN foi desenvolvida primeiramente utilizando os dados da estação meteorológica de Curitiba-PR, os dados observados no período de 01 de dezembro de 2008 até 04 de setembro de 2010. Os dados do pluviômetro são medidos em um intervalo de 15 minutos e à cada hora, já os dados do radar são obtidos em aproxiamadamente 10 minutos, então fez-se a média horária para a comparação. Escolheu-se os dados de refletividade do radar do dia 01 de abril de 2011 para aplicar a rede neural, neste dia ocorreu uma forte tempestade na região de Curitiba, o que torna interessante a visualização. 


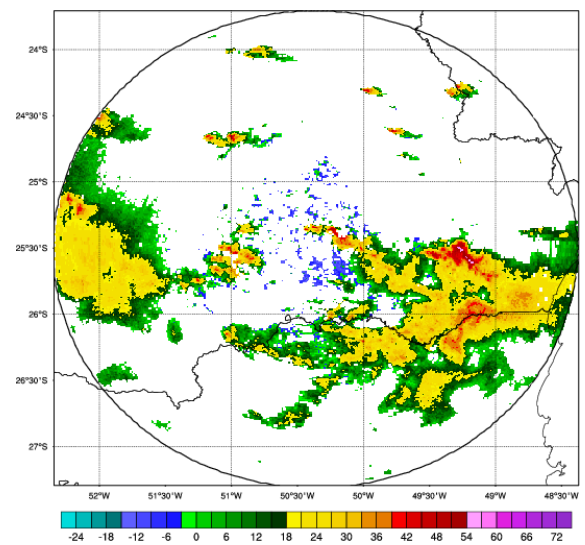

Figura 3: Imagem de Refletividade do Radar.

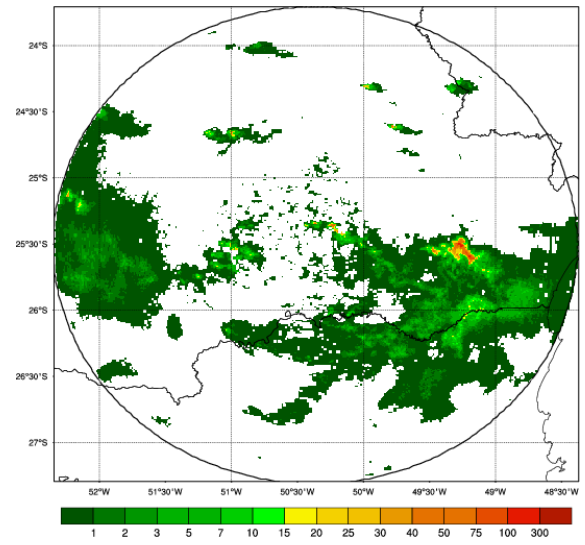

Figura 4: Relação ZR - Imagem de Estimativa de Chuva.

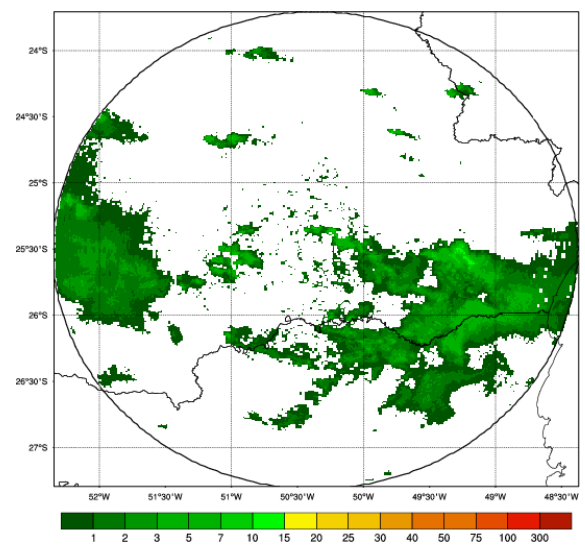

Figura 5: Rede Neural - Imagem de Estimativa de Chuva.

Com as imagens acima é fácil notar a similaridade da Relação ZR com a RBFNN, o padrão do evento meteorológico foi mantido. Como segunda etapa, desenvolveu-se a rede neural com os dados de 15 pluviômetros deixando os dados das estações de Antonina-PR, Guarapuava-PR e União da Vitória-PR para testes e validação. O gráfico abaixo mostra a comparação entre os pluviômetros, a relação ZR e o resultado obtido da RBFNN. 


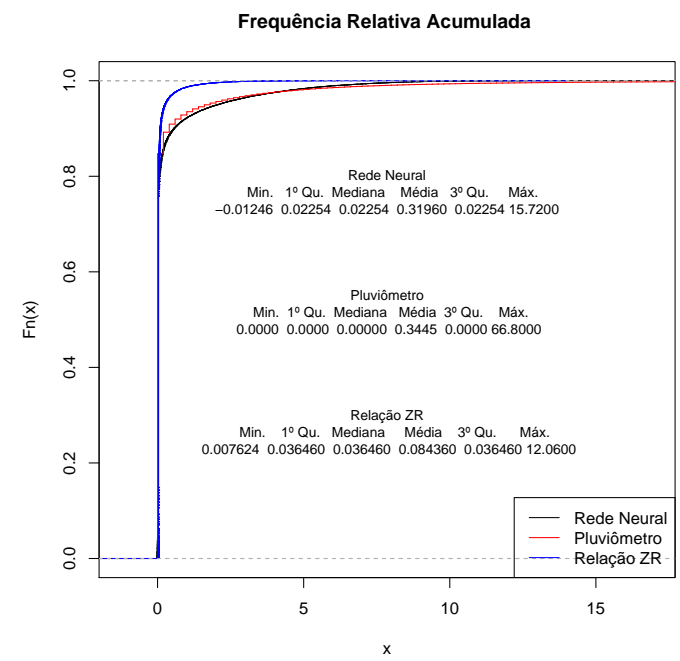

Figura 6: Gráfico da Frequência Relativa Acumulada.

A partir da análise do gráfico de frequência relativa acumulada, bem como dos valores extremos e médios pode-se concluir que os dados obtidos através da Rede Neural aproximam-se muito mais dos dados coletados através dos pluviômetros do que os dados convertidos com a Relação ZR.

\section{Próximas Etapas}

Sabendo da necessidade de se realizar testes mais consistentes para a comparação dos resultados, pretende-se analisar o tempo computacional para as diferentes configurações da rede neural, conhecendo o fato de que quanto maior a quantidade de neurônios na camada oculta, maior será a dimensão da matriz pseudo-inversa calculada no processo além de utilizar o valor máximo da refletividade do radar em cada hora ao invés da média dos valores. A Rede Neural de Base Radial também será utilizada para a conversão de dados de refletividade em estimativa de chuva nos dados dos radares do IPMet/Unesp localizados nas cidade de Bauru-SP e Presidente Prudente-SP.

\section{Referências}

[1] Beneti, C. \& Nozu, I. \& Saraiva, E. A., 1999. Monitoramento da precipitação e de eventos de tempo severo com radar meteorológico no estado do Paraná. Relatório Técnico, SIMEPAR.

[2] da Mota, J. F. \& Siqueira, P. H. \& de Souza, L. V. \& Vitor, A., 2011. Uma rede neural de base radial baseada em computação evolucionária. XXXII CILAMCE.

[3] Haykin, S., 2001. Redes Neurais: princípios e prática (Tradução de Paulo Martins Engel). Bookman, Porto Alegre, Brasil.

[4] Mueller, B. Radar equation. Disponível em: <http://wx.db.erau.edu/faculty/mullerb/Wx365/ Radar_equation/radar_equation.pdf $>$. Acesso em 20 de jul. 2013.

[5] Rinehart, R. E., 2004. Radar for Meteorologists. Rinehart Publications, Nevada, USA. 